\title{
NOTAS SOBRE LAS IX JORNADAS DE HISTORIA ECONOMICA ARGENTINA
}

\author{
JUAN HERNANDEZ ANDREU \\ Universidad Complutense
}

Del 20 al 22 de octubre pasado se celebraron en Buenos Aires las IX Jornadas Nacionales de Historia Económica, organizadas por el Instituto de Investigaciones de Historia Económica y Social (IIHES) de la Facultad de Ciencias Económicas de la Universidad de Buenos Aires y la Asociación Argentina de Historia Económica. El Comité organizador lo constituyeron Mario Rapoport (Director del IIHES), Jorge Gilbert, Eduardo Azcuy Ameghino, Mercedes Avogadro y Lidia Knecher. El marco de las Jornadas fue la celebración del 75 aniversario de la creación de la Facultad de Ciencias Económicas de la Universidad Nacional de Buenos Aires. Se presentaron 51 ponencias; se pronunciaron varias conferencias a cargo de Juan Hernández Andreu (conferencia inaugural), Aldo Ferrer, Manuel Burga y Roberto Cortés Conde; y se desarrollaron "paneles» o sesiones de debate entre especialistas sobre: «Producción y relaciones sociales en el Virreinato del Río de la Plata», "¿Integración o desintegración?: Las economías regionales en los siglos XIX y $x x » y$ « ¿Economía agroexportadora o industrialización?: La inserción de Argentina y Brasil en la economía mundial de entreguerras».

Seguidamente voy a limitarme a presentar un resumen de las ponencias que responden a temas de Historia Económica del siglo xx de Argentina y de otros países de Latinoamérica; la selección obedece no sólo a razones de propia especialidad, sino, sobre todo, de espacio. El orden que sigo en la presentación de las ponencias obedece al simplemente alfabético.

Guillermo Bravo Acevedo señala en su ponencia ( «Estudio regional de la crisis de 1929 en Chile: Consecuencias económicas y sociales en la sociedad salitrera") que el alcance de la crisis de 1929 en Chile es más conocido en el aspecto económico que en el social y, sobre todo, por las alteraciones macroeconómicas que produjo, tanto en el precio y volumen de las exportaciones como en el significativo desequilibrio de la balanza de pagos. Sin embargo, los efectos socioeconómicos regionales de la Gran Depresión, especialmente los de la sociedad salitrera, no han merecido estudios historiográficos; en el campo de los efectos económicos destaca el cierre de las oficinas salitreras, una con- 
siderable baja en la producción de salitre y una importante disminución de las exportaciones del nitrato. Naturalmente, estos factores afectaron directamente la balanza comercial y la de pagos del país. Pero, consecuentemente, en el ámbito regional hubo una gran cesantía que derivó en una pésima situación económico-social de la población, especialmente de las ciudades de Iquique y Antofagasta, que formaban los núcleos urbanos más desarrollados de la zona. La fuerza del impacto económico trajo una serie de problemas sociales tales como: falta de viviendas y encarecimiento de los arriendos. carestía de alimentos y carencia de ellos, deterioro de la salud de la población, desarrollo de la delincuencia, mendicidad y prostitución, entre otros. Por otra parte, también se vieron afectadas las tasas de natalidad, nupcialidad, mortalidad y migración en el aspecto demográfico.

Liliana Cattáneo, en su estudio «El panamericanismo, las potencias anglosajonas y los grupos económicos en la Argentina (1930-1941)», observa un cambio, a lo largo del decenio, en la percepción de la relación anglo-argentina. Ella se desliza con distintos ritmos, de un modelo organizado en torno a la convicción en la "relación especial» que uniría a Argentina con Inglaterra, hacia una visión mucho menos optimista que cuenta entre sus elementos la noción de «decadencia» de Gran Bretaña. Si bien esta transformación es menos evidente en alguna de las fuentes consultadas, se entiende que podría estar relacionada con procesos similares, que afectaban, por ejemplo, a algunos grupos políticos, y que estaban teniendo lugar en la sociedad global. Enlazada con esta cuestión, aparece la relativa demora en la valoración de la alternativa norteamericana frente a la inglesa. El impacto provocado por la Segunda Guerra Mundial modificó, naturalmente, posiciones y actitudes. En lo que se refiere específicamente al tema panamericano, su ausencia es notoria en las publicaciones argentinas, lo cual explica el escaso interés que sectores dirigentes argentinos mostraron, antes de la Segunda Guerra Mundial, por los debates políticos, económicos y militares, que tuvieron lugar en las conferencias regionales.

Raúl García Heras, en su trabajo «Los ferrocarriles británicos y el control de cambios en la Argentina durante la Gran Depresión», señala que hacia 1930 un 13,5 por 100 de las inversiones británicas en la Argentina estaban localizadas en títulos del Gobierno, un 24,1 por 100 en empresas diversas, y un 62,3 por 100 en compañías ferroviarias privadas. Estas últimas indican la presencia británica en la economía argentina y desde finales del decenio de 1920 sus valores bursátiles devengaban regularmente ganancias que oscilaban entre un 4,9 y un 5,5 por 100 anual. La Gran Depresión y el golpe de 1930 que derrocó al gobierno radical y dio lugar a una restauración conservadora en la Argentina inauguraron años de crecientes problemas, desconocidos hasta entonces, para las compañías ferroviarias y el gobierno británico. 
Este estudio analiza la política de control de cambios en la Argentina entre 1931 y 1933, su repercusión sobre las empresas ferroviarias británicas, la actitud del gobierno británico ante ambos fenómenos en un momento decisivo para las relaciones anglo-argentinas. No se entra directamente en el debate general sobre el imperialismo y la dependencia en América Latina porque esta discusión ya ha alcanzado un alto nivel de abstracción, en tanto que todavía hacen falta estudios concretos de las operaciones y evolución de empresas de propiedad extranjera radicadas en la región. Se trata de plantear nuevos argumentos destacables para la discusión de puntos centrales en ambas teorías a través de un análisis empírico, que asimismo contrastara los hallazgos de Platt para este caso.

La historia del sector agrario es clave para comprender la realidad económica argentina, y Eugenio Gastiazoro nos ofrece una ponencia titulada «Elementos para el estudio de la cuestión agraria argentina: 1969-1988». El conocimiento de la estructura de la tenencia de la tierra en Argentina es difícil, ya que los datos catastrales son difícilmente accesibles. Por razones fiscales o de otro orden, los grandes terratenientes han subdividido muchos de sus latifundios en extensiones incluso menores de 1.000 hectáreas, transformando a cada una de las «fracciones» en una sociedad anónima distinta, práctica que ya fuera señalada por Weil en el decenio de 1940.

Partiendo de los datos del Censo Nacional Agropecuario de 1969, publicado en 1975, Gastiazoro observa que el 6 por 100 de las explotaciones, que suman 32.579, dispone de nada menos que 156,4 millones de hectáreas, casi el 75 por 100 de la tierra censada. Mientras que el otro extremo, en los establecimientos de hasta 100 hectáreas, sumamos 350.065 , casi el 70 por 100 del total de las explotaciones, que disponen de apenas 10 millones de hectáreas, o sea, un magro 5 por 100 de la tierra utilizable del país. Se muestra el neto predominio del latifundio, y también su secuela inevitable: el minifundio y la falta de tierra cultivable para los campesinos pobres y medios. Con el agravante que, en general, las pocas tierras que disponen estos sectores son tierras bastante agotadas porque sus poseedores no tienen capacidad de rotación y en las condiciones actuales resulta antieconómico el uso de fertilizantes y abonos en forma significativa. Por otra parte, y este dato ilumina con intensidad el sistema de propiedad y tenencia de la tierra, casi la mitad de esas 350.065 explotaciones no son trabajadas por sus propietarios, sino bajo las diversas formas de arriendo, con la inseguridad que ello entraña para el campesino trabajador.

Adela M. Harispuru analiza la «Incidencia de la declaración de la Primera Guerra Mundial sobre el consumo interno (1914-1916)». Se examina en este trabajo la evolución de los precios de los insumos más necesarios, los problemas derivados de su escasez y de la especulación. El desarrollo del tema 
es puntual, atendiendo a la reacción gubernamental frente a una economía de guerra, sin desprenderse de su liberalismo a ultranza. Las consecuencias de un programa incoherente para dominar la situación, sólo basado en medidas aisladas, no permitió alcanzar más que soluciones parciales. Paralelamente, el proceso que se plantea, y que arrancara aun con los coletazos de la crisis agraria de 1913, continuó como sustrato de los cambios políticos. Expuesto el tema como mera coyuntura, sólo serviría para hacer acopio de cifras sobre el interregno Sáenz Peña-Irigoyen, y el ascenso al gobierno del radicalismo en 1916. Sin embargo, lo que se pretende es aportar datos de una de las variables del conflicto social, el consumo en el mercado interno, trabajo que debería ampliarse con la evolución de los salarios y los índices de paro, para establecer así el panorama de la situación social durante la Primera Guerra.

Esteban Miller presenta una investigación sobre «La aplicación del Plan Marshall y sus repercusiones en el comercio exterior argentino». Algunos autores han argumentado que el gobierno de Perón (1945-1955) no llevó a cabo una buena política agropecuaria, favorable a la expansión productiva, y provocó una mejor participación de las exportaciones argentinas de alimentos en el comercio mundial. Este trabajo pretende ilustrar, utilizando estadísticas y datos conocidos, que la política peronista no fue el principal factor en la caída de la producción experimentada entre 1949 y 1952. La explicación hay que buscarla, por una parte, en las condiciones climáticas, que afectaron a toda la producción agro-ganadera, y, por otro lado, en la caída de la demanda europea, que fue satisfecha en ese período por los alimentos norteamericanos del Plan Marshall y, posteriormente, por los propios países de Europa integrados en la Comunidad Económica. De este modo el Plan Marshall vino a satisfacer las necesidades de alimentos de los países europeos y cubrió gran parte de las exportaciones que antes correspondían a Argentina. Así se explica cómo siendo, entre 1948 y 1949, la caída de la producción de cereales y granos oleaginosos (productos de exportación) de un 37 por 100, el descenso del volumen de exportaciones a Europa fue del 76 por 100 . El envío de alimentos desde Estados Unidos (exportaciones tradicionales más los previstos por el plan) a Gran Bretaña aumentó casi un 50 por 100 entre 1948 y 1949; y la participación del Reino Unido sobre el total de las exportaciones argentinas a Europa occidental cayó de un 40 a un 25 por 100 entre 1948 y 1952. Respecto a uno de los principales productos argentinos de exportación, el trigo, se observa que la participación europea sobre el total de las exportaciones disminuye un 15 por 100 entre 1948 y 1949, manteniéndose en ese nivel durante los años del Plan Marshall, con excepción del año 1952, donde sí se nota una influencia directa de la oferta.

Andrés Musacchio presentó la ponencia «Comercio y política: Las relaciones argentino-alemanas (1930-1939)». Cuando se analizan las relaciones 
entre Argentina y Alemania en la década de 1930, se perciben tres momentos claramente definidos. Entre 1930 y 1934 hay un deterioro progresivo de la relación comercial, que tiene estrecha relación con la crisis económica mundial y su repercusión en las coyunturas internas. La destrucción del sistema multilateral de comercio produce estragos en el comercio bilateral de los dos países. Las políticas destinadas a superar la crisis que se imponen en ambas naciones agrava el problema. La mala situación externa alemana con relación a las divisas le lleva a buscar una reducción del déficit comercial contrayendo las importaciones, lo cual genera un malestar en Argentina que se revierte en dificultades para otorgar permisos de cambio a los importadores de productos alemanes, volviéndose nuevamente al principio, produciéndose de esa forma un círculo vicioso. Entre 1934 y 1937 se intenta un acercamiento entre ambas partes que evita que ese deterioro siga su marcha, aunque no logra invertir claramente la tendencia. Este periodo tiene particularidades significativas dentro de una relación que tiene como punto central las vinculaciones económicas. Entre 1938 y 1939 se observa en Alemania una intensificación de la lucha de dos grupos internos por el control de la política exterior. Por un lado, la Auswartiges Amt plantea la necesidad de mantener como centro la política comercial y cultural, mientras que, por el otro, la Auslandsorganisation (Organización de los Alemanes en el extranjero) busca trasladarlo a la política de propaganda y conservación del germanismo, aun a costa de resentir las relaciones diplomáticas.

Musacchio plantea en dos acontecimientos esta dicotomía con crudeza. El primero tiene lugar en julio de 1938 , cuando se reúnen los jefes de las misiones de Argentina, Brasil, Chile y Uruguay para analizar su actitud frente a esta posición contradictoria, sugiriendo a las autoridades alemanas permanecer ocupándose de cuestiones económicas, ya que, de lo contrario, se le allanaría el camino del panamericanismo a los Estados Unidos. El segundo se produce en el marco de la Conferencia Iberoamericana de Berlín, en donde participan los embajadores latinoamericanos, los jerarcas de la Auslandsorganisation y los encargados de la Auswartiges Amt. Allí es donde el campo de tensión llega a su punto máximo, sin lograr una definición por parte de Hitler. Mientras tanto, las relaciones con Argentina empeoran nuevamente a causa de las actividades de los grupos nacionales-socialistas.

Finalmente, Mario Rapoport y Jorge Carrizo presentaron el estudio «Estados Unidos y el peronismo: Estrategias económicas y políticas, 1945-1955. Una nota preliminar». En esta ponencia se señala que la política de Estados Unidos hacia la Argentina en el período mencionado respondió al peso de diferentes sectores internos norteamericanos y sufrió diversos cambios en función de la percepción e influencia de los mismos. Perón, por su parte. tenía coincidencias estratégicas con las posiciones estadounidenses, pero con- 
cebía el mejoramiento de las relaciones con EE. UU., deterioradas desde la Segunda Guerra Mundial, dentro de una línea de negociación y no de subordinación, lo que constituía un obstáculo para lograr ese objetivo.

Como advierten Rapoport y Carrizo, si bien hay un acercamiento entre los dos países a partir de mediados de 1947, siguen existiendo fuertes presiones para remover todos los aspectos indeseados de la política económica peronista, particularmente su resistencia a abandonar el bilateralismo e integrarse a los organismos multilaterales de comercio y pagos surgidos en Breton Woods.

Dos factores significativos obstacularizaron las relaciones económicas argentino-norteamericanas. Por un lado, la inconvertibilidad de las monedas europeas - sobre todo la libra y el franco-, que impedían a la Argentina la obtención de los dólares necesarios para pagar los productos norteamericanos y continuar el intercambio triangular característico de la preguerra. Por el otro, la disminución de los excedentes agrícolas exportables argentinos (agravada por las sequías de 1949-50), que limitaba su capacidad para comprar mercaderías y equipos en el extranjero.

La frustrada participación argentina en el Plan Marshall, debido en gran medida a la colocación por los norteamericanos de sus propios excedentes agrícolas, y los propios errores de la política peronista, condujeron las relaciones a un impasse que sólo se supera con la llegada de la nueva administración republicana en EE. UU. y con un enfoque diferente de las relaciones económicas internacionales por parte del gobierno argentino.

A partir de 1953, se producirá un giro sustancial en el tratamiento de las inversiones extranjeras que beneficia a empresas norteamericanas, y se procurará incrementar las relaciones comerciales, políticas y militares entre los dos países. Pero, paradójicamente, como puntualizan Rapoport y Carrizo, esto, en vez de ayudar al régimen, contribuirá a su caída, en septiembre de 1955 , porque la oposición política retoma las banderas nacionalistas del primer peronismo criticando acerbamente ese nuevo, y ahora más profundo, acercamiento con EE. UU.

A través de esta selección de ponencias puede observarse el notable interés que tiene para los historiadores de la economía española e internacional conocer el acopio de nuevas investigaciones que lleva a cabo la historiografía económica argentina. 